\title{
Female Urethroplasty for a Childbirth Related Stricture: A Case Report
}

\author{
Marjan Waterloos ${ }^{1}$, Wesley Verla ${ }^{2}$, Anne Françoise Spinoit ${ }^{2}$ and Nicolaas Lumen ${ }^{2 *}$ \\ ${ }^{1}$ Department of Urology, Algemeen Ziekenhuis Maria Middelares, Belgium
}

${ }^{2}$ Department of Urology, Ghent University Hospital, Belgium

Submission: December 14, 2018; Published: December 20, 2018

*Corresponding author: Nicolaas Lumen, Department of Urology, Ghent University Hospital, Belgium.

\begin{abstract}
This article describes a case report of a female who suffered a 23-year long history of urethral stricture disease after a childbirth injury to the urethral meatus and anterior vaginal wall. Despite different attempts of urethral dilations and urethrotomies, the stricture and the obstructive complaints persisted affecting the patient's quality of life. The patients were finally treated with a dorsal only urethroplasty using a buccal mucosa graft. This was combined with local resection of abundant inflammatory scar tissue at the ventral vaginal wall and urethral meatus. This case report will emphasize on the clinical decision making and the tools used for this as well as on the surgical technique and postoperative care.
\end{abstract}

Keywords: Urethral stricture; Inflammatory; Postoperative care; Urologic; Diagnosis; Infections; Urethrotomies; Cysto-urethroscopy; Proximal urethra; Dorsal onlay; Vestibulum

\section{Introduction}

Reports on diagnosis and treatment of female urethral strictures are rare in urologic literature, as opposed to male urethral stricture disease. Nevertheless, female urethral stricture disease might cause severe obstructive and irritative voiding symptoms as well with a substantial impact on the patient's quality of life. There are no exact data on the incidence of female urethral stricture disease [1-3]. There is no international consensus nor any guideline on how to diagnose or treat female urethral strictures. Herein, we describe the case of a female suffering a long-standing history of urethral stricture disease finally treated with dorsal onlay buccal mucosa graft urethroplasty with emphasis on the diagnostic work-out, surgical technique and postoperative care.

\section{Clinical Case Description}

\section{Previous urological history}

A 51-year old female consulted a reconstructive urologist (M.W.) with complaints of painful micturition, incomplete emptying of the bladder, recurrent urinary tract infections, a weak urinary stream and urgency but without any incontinence. She suffered an anterior vaginal laceration extending into the urethral meatus during childbirth 23 years ago. This injury was primarily sutured but no further details on the technique could be obtained from her medical file. Shortly thereafter, she developed the above-mentioned complaints. Numerous $(>10)$ dilations and internal urethrotomies have been performed with only a short temporarily relief of the symptoms.

\section{Diagnostic workout}

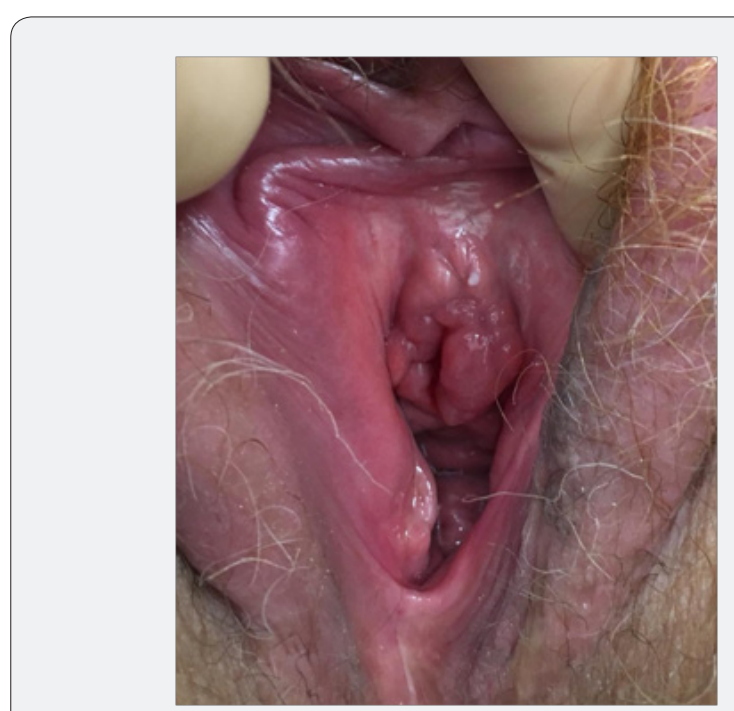

Figure 1: Clinical inspection of the vulva revealing inflammatory scar tissue at the vaginal anterior wall just below the urethral meatus. 


\section{Juniper Online Journal of Case Studies}

Clinical gynecological examination revealed abundant inflammatory and indurated tissue just below the urethral meatus (Figure 1). This scar tissue was painful during digital palpation.

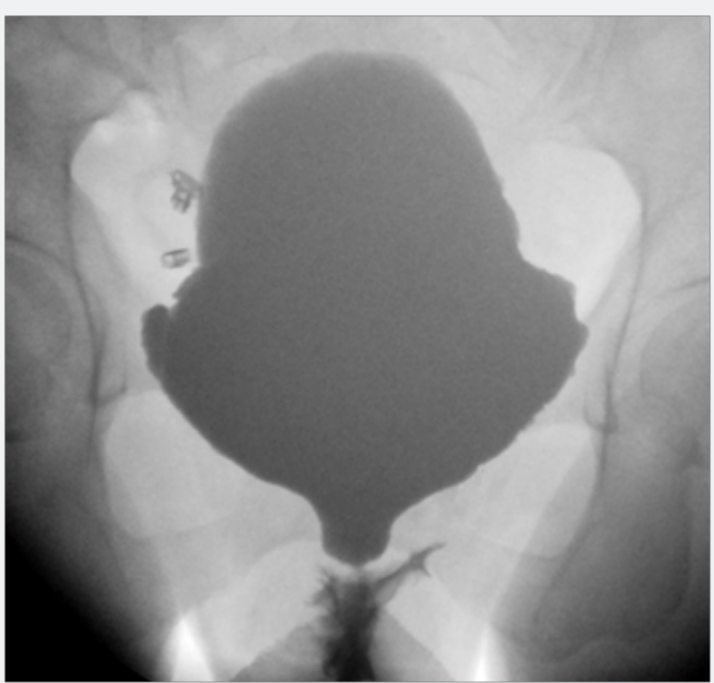

Figure 2: Voiding cysto-urethrography with a distal female urethral stricture and prestenotic dilation ("wine glass image").

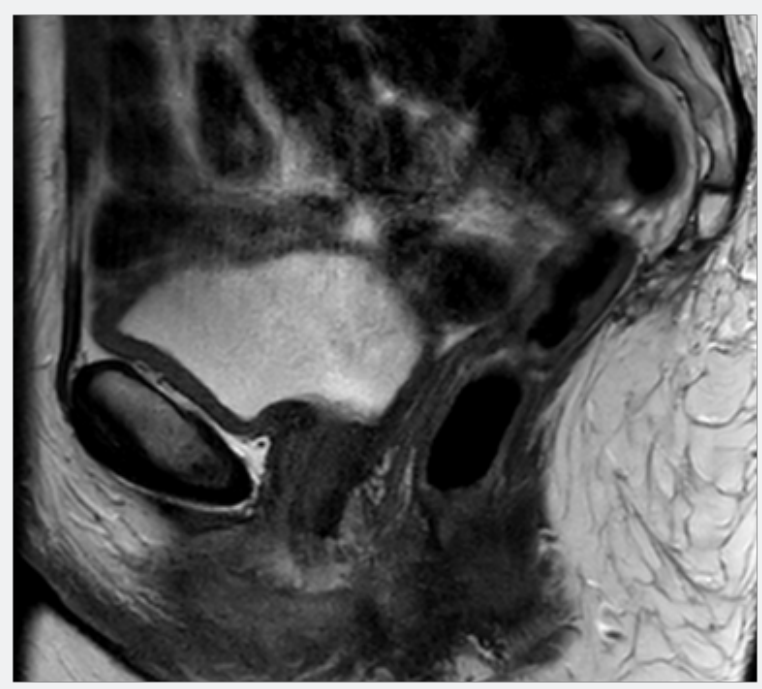

Figure 3: MRI (T2 weighted image) of the female pelvis. The urethra is clearly visible without the presence of a urethral diverticulum or peri-urethral abscess.

Uroflowmetry showed a plateau-shaped obstructive voiding curve with a maximum urinary flow of $11 \mathrm{ml} / \mathrm{s}$. Cystourethroscopy was poorly supported because of local pain and not possible because the stricture started directly at the meatus. A 10Fr urethral catheter could not be passed into the bladder. Voiding cysto-urethrography (VCUG) was performed after a $5 \mathrm{Fr}$ feeding tube was introduced into the bladder. VCUG showed a distal urethral and meatal stricture with a remarkable dilation of the proximal urethra (Figure 2). Pelvic MRI was performed to exclude any peri-urethral abnormalities. Especially, we wanted to exclude an infected urethral diverticulum or a peri-urethral abscess because of the observed local inflammation. However, MRI was negative for this (Figure 3).

After counseling the patient, it was decided to perform a dorsal onlay urethroplasty with a buccal mucosa graft and excision of the inflammatory scar tissue surrounding the ventral circumference of the urethral meatus. A preoperative urine culture was sterile.

\section{Surgical technique}

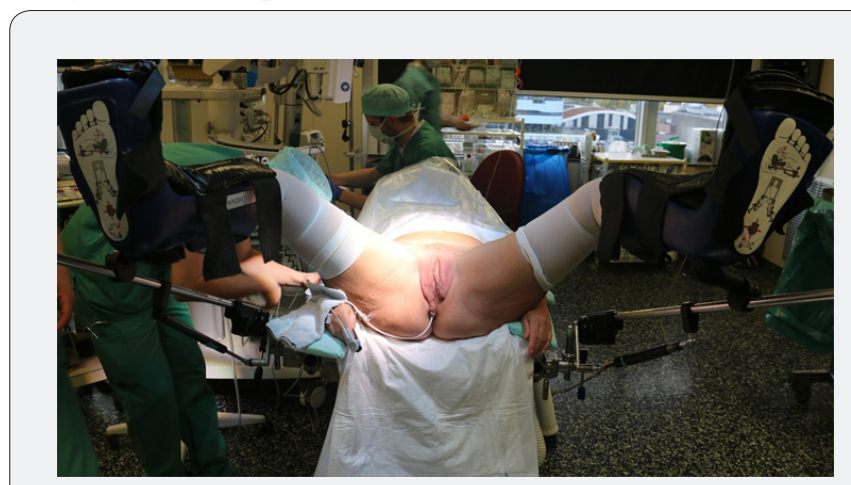

Figure 4: patient positioning.

The operation was performed by 2 urethral surgeons (M.W. and N.L.). Prophylactic antibiotics were administrated (1g cefazoline) at induction of general anesthesia. The patient was placed in the lithotomy position with the hips and knees $90^{\circ}$ flexion and the legs $45^{\circ}$ abduction. The buttock was slightly over the end of the operation table. The feet and lower legs were placed in supportive boots (Figure 4). The surgical field was disinfected using a povidone-iodine solution. Nasal intubation was performed, and the oral cavity was disinfected with chloramine solution in aqua. The labia minora were retracted by a self-retaining hook retractor in order to have a good exposure of the vestibulum, the urethral meatus and the vaginal introitus. A guidewire (5Fr feeding tube) was placed through the urethra inside the bladder in order to avoid creation of false passage during opening of the stricture (Figure 5).

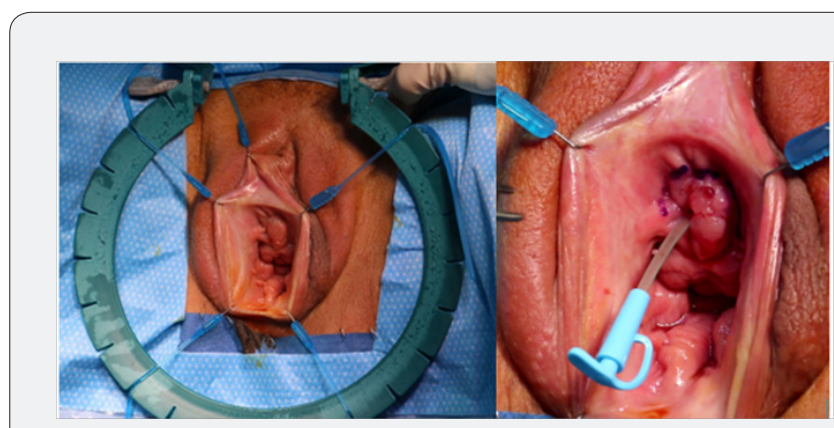

Figure 5: exposure of the surgical field using a self-retaining hook retractor (left). A $5 \mathrm{Fr}$ feeding tube was placed through the urethra as guidewire. The incision line is already marked (right).

A semi-lunar suprameatal incision was made (Figure 5). The plane between the clitoris bodies and the dorsal urethra 


\section{Juniper Online Journal of Case Studies}

was carefully dissected. The pubic bone was digitally palpated and marked the point of proximal dissection. The urethra was progressively opened at the dorsal side and stay sutures were immediately placed at the urethral edges (every centimeter) to facilitate further identification of the urethral mucosa. The stricture was further opened until healthy proximal urethra was encountered which allowed passage of a $25 \mathrm{Fr}$ metal sound (Figure 6).
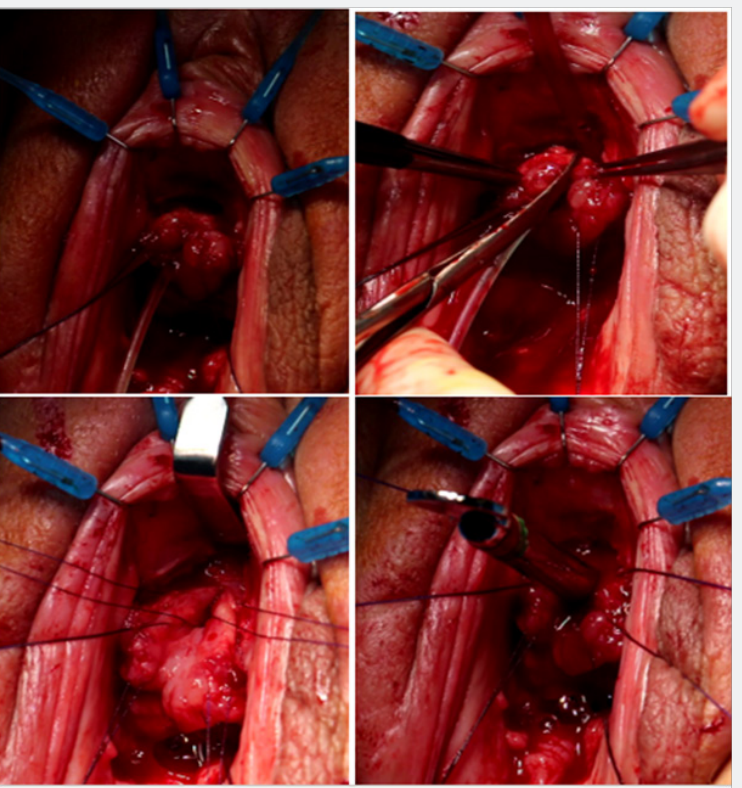

Figure 6: opening of the stricture. Semi-lunar suprameatal incision (upper left). Incision at the dorsal surface of the urethra (upper right). Stay sutures placed to identify the urethral mucosal edges (lower left). Identification of healthy proximal urethra by passing a $25 \mathrm{Fr}$ metal sound.
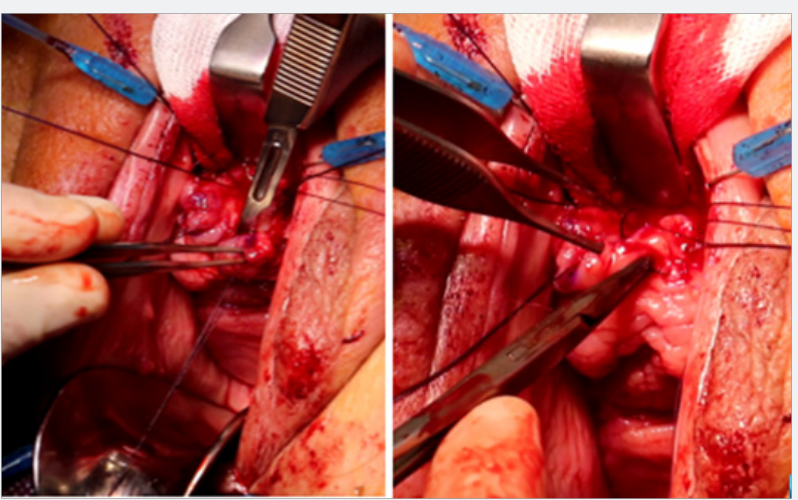

Figure 7a: resection of the ventral inflammatory scar tissue (left) and approximation of the ventral meatal edge to the vaginal mucosa of the anterior wall.

The ventral scar tissue was locally excised until healthy urethral and vaginal mucosa were left over at the ventral aspect of the meatus. The edges were approximated to each other using monocryl ${ }^{\text {TM }} 4.0$ separate sutures. At that stage, a Doyen's blade was placed at the posterior vaginal wall to further expose the anterior vaginal wall (Figure 7).

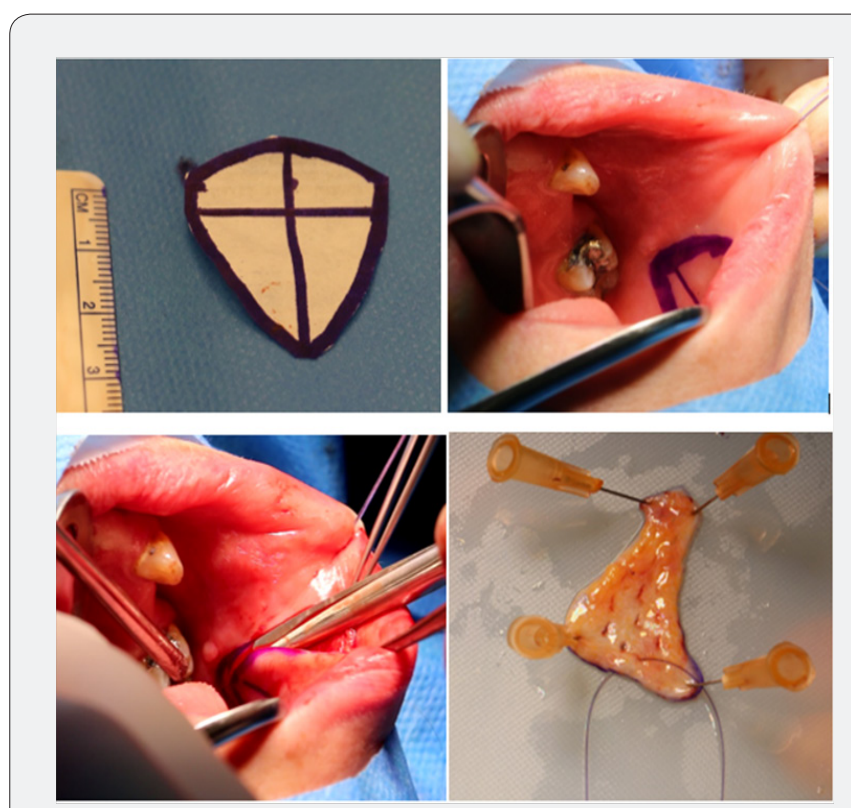

Figure 7b: Harvest of a slightly triangular buccal mucosa graft.
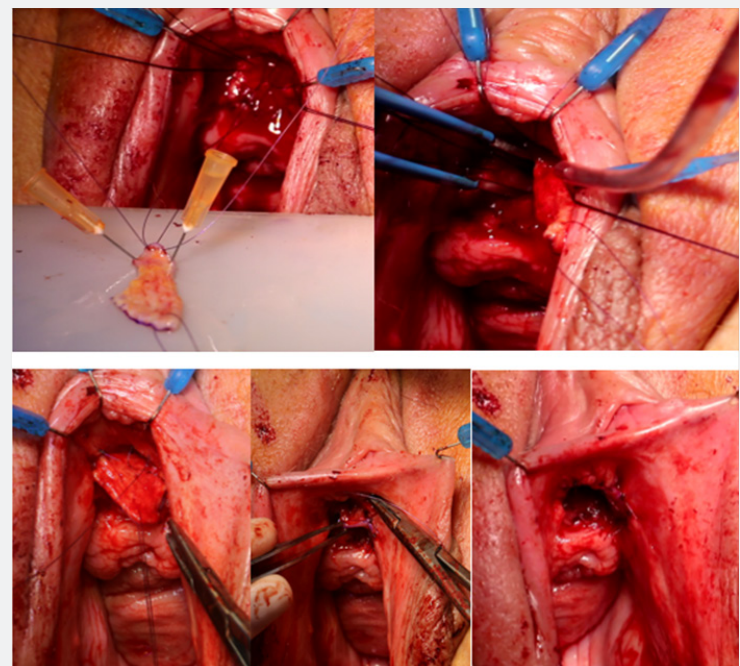

Figure 8: Dorsal onlay buccal mucosa graft urethroplasty. The graft is presented and sutured to the proximal urethra with 2 stitches monocryl ${ }^{\mathrm{TM}} 4.0$ (upper left). Running suture on the right side(upper right). Quilting of the graft to the corporal bodies (lower left). Suturing of the distal graft to the suprameatal incision (lower mid). Final result (lower right).

A graft was harvested according to the dimensions of the stricture. In this case, a slightly triangular graft was harvested of $3 \mathrm{~cm}$ long and $2.5 \mathrm{~cm}$ width. A mouth retractor was used, and the dimensions of the graft were projected at the inner surface of the left cheek with respect for the orifice of Stenon's duct. The buccal mucosa was infiltrated with a diluted solution of xylocain with adrenalin as a measure of hydrodissection. Dissection was 
performed using Jones scissors in a submucosal plane above the buccinator muscle. Hemostasis was achieved using bipolar coagulation and the donor area was further left open. The graft was carefully defatted on a silicone plate and meshed. During preparation of the graft, the graft was held wet constantly. A stay suture was placed at the distal end of the graft (Figure 7b).

The graft was transferred to the acceptor area, presented on the silicone plate. The proximal end of the graft (the tip) was sutured to the proximal end of the opened urethra with 2 sutures monocryl ${ }^{\mathrm{TM}}$ 4.0. The mucosal surface of the graft was turned towards the urethral lumen and the knots of the suture were outside the lumen. These monocryl ${ }^{\mathrm{TM}}$ sutures were further used to approximate the edges of the graft to the edges of the opened urethra on both sides in a running suture fashion from proximal to distal. This suturing also included the peri-urethral tissues in order to have a good fixation of the graft to the surrounding tissues. In addition to this, the graft was centrally quilted to the clitoral bodies with separate monocryl ${ }^{\mathrm{TM}} 4.0$ sutures. At the meatus, the distal end of the graft was sutured to suprameatal incision using separate stitches monocryl ${ }^{\mathrm{TM}} 4.0$ (Figure 8).

At the end of the operation, a 20Fr catheter was inserted, and a fatty gauze was wrapped around this catheter and pushed against the grafted meatus. A vaginal packing was inserted as well for hemostatic reasons (Figure 9). The oral cavity was checked for bleeding before extubation. Operation time (skin-toskin) was 125 minutes.

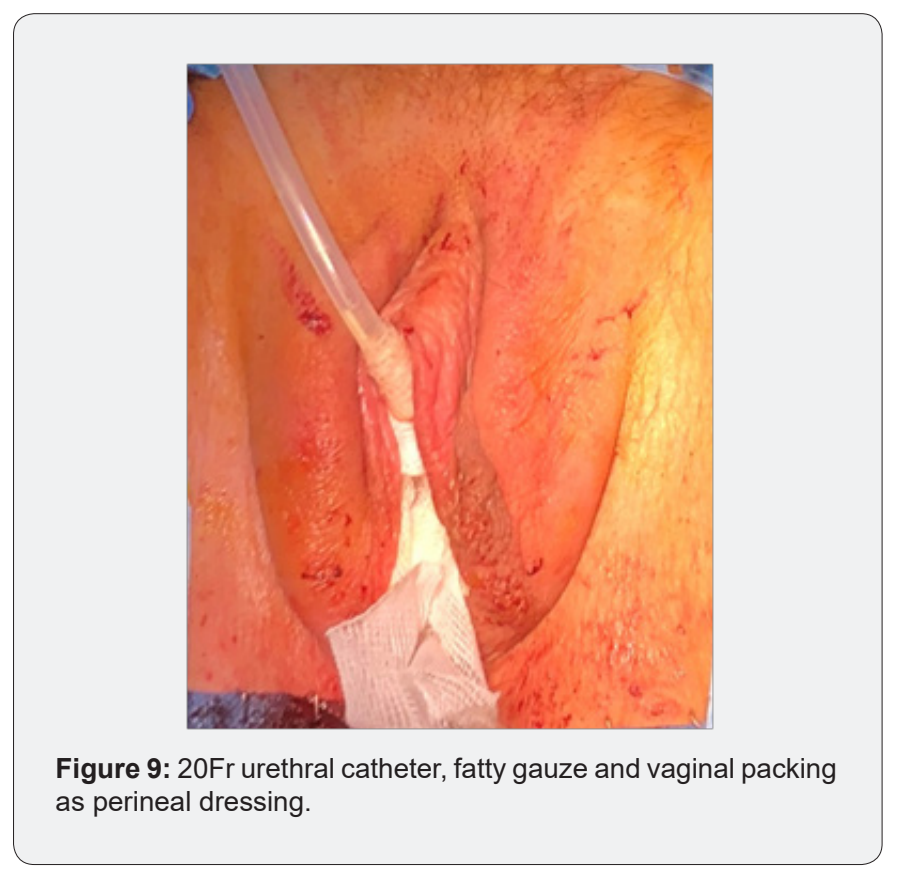

\section{Postoperative care and follow-up}

At the recovery, amoxicillin + clavulanic acid $3 \times 500 \mathrm{mg}$ and oxybutynin $3 \times 5 \mathrm{mg}$ daily were initiated until catheter removal. After $3 \mathrm{~h}$, patient went back to the standard hospital room. The oral cavity was washed morning and evening, and after every meal with corsodyl ${ }^{\mathrm{TM}}$ during 2 weeks. The vaginal packing was removed after one day. The patient was discharged at the 2nd postoperative day without any problems. The catheter was removed after 2 weeks with VCUG showing a patent urethra and no signs of extravasation (Figure 10). Upon clinical examination, there were no wound healing problems. The resected tissue was inflammatory but not malignant upon pathological examination.

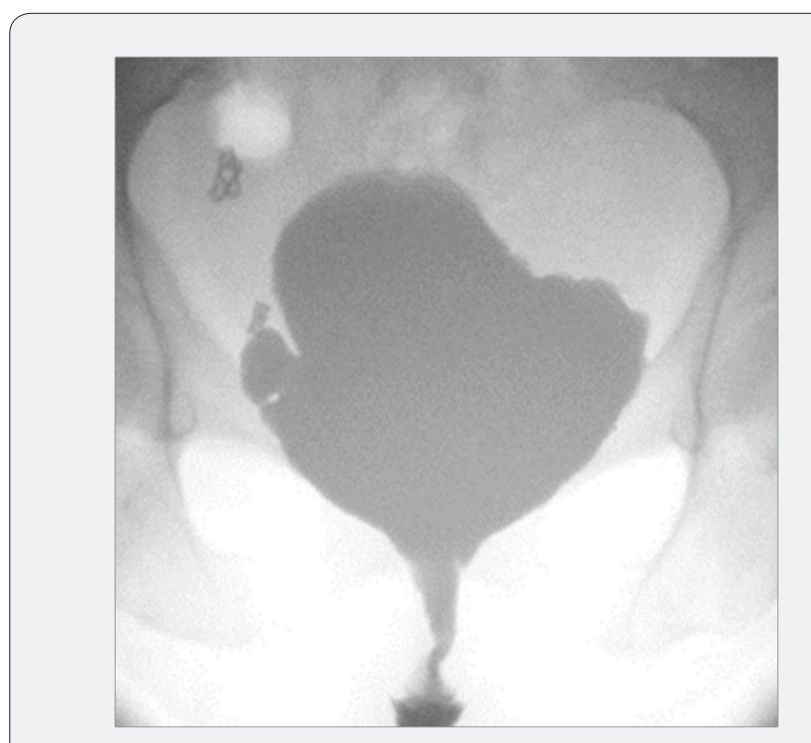

Figure 10: Postoperative VCUG showing a normal urethral caliber.

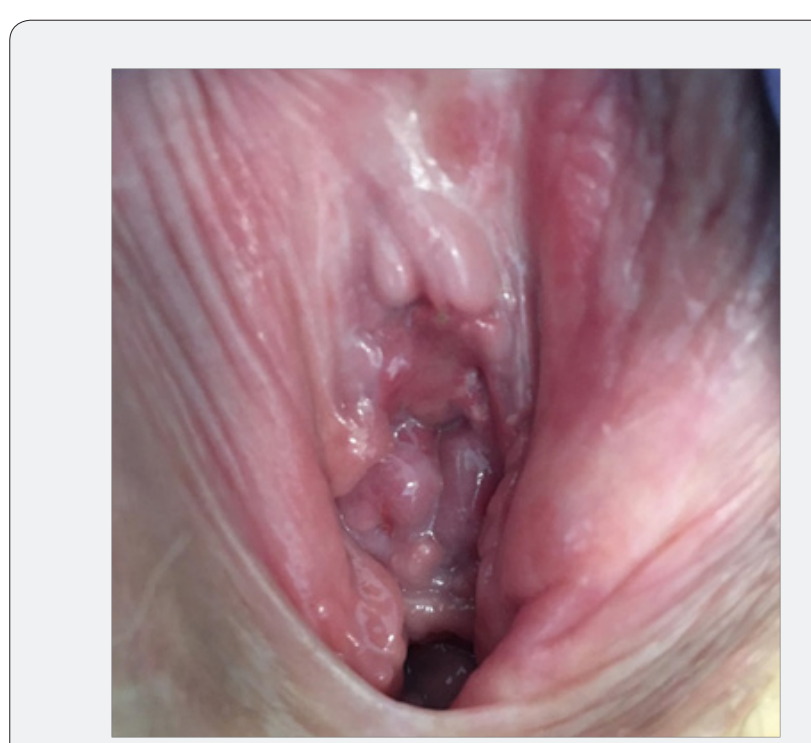

Figure 11: Postoperative situation with healing of the buccal mucosa graft.

At the next postoperative visit (after 3 months), patient reported no voiding difficulties and absence of pain. There was no incontinence. She was very satisfied with the result. Clinical examination showed no abnormalities and a well healed graft in the urethral meatus (Figure 11). The urethra allowed passage of a $14 \mathrm{Fr}$ cystoscope without signs of narrowing. The patient provided written informed consent for anonymous publication of this case report. 


\section{Comment}

Only $10 \%$ of women who consult a urologist with obstructive voiding will have a true ("anatomical") urethral stricture [13]. In this case, stricture etiology was the consequence of childbirth injury. Obsteteric urethral injuries are an import etiology of female stricture formation [2,4]. Frequently reported complaints are a weak urinary stream, sensation of incomplete voiding, straining, frequency and nocturia [5,6]. As in this case, many women also experience pain during micturition, urgency $[1,3,6,7]$ and suffer recurrent urinary tract infections $[3,5,6,8]$. In women with lower urinary tract symptoms, uroflowmetry must be part of the diagnostic work-out and a plateau-shaped curve is suggestive for a stricture [9]. A gynecological examination is indispensable as it might directly reveal a meatal stenosis and the presence of lichen sclerosus, pelvic organ prolapses or periurethral abnormalities. This examination must also emphasize on the quality of local tissues which might be used for urethral reconstruction $[1,2]$. In this case, the presence of inflammatory scar tissue at the ventral aspect of the meatus revealed during gynecologic examination was important for the choice of technique. In the present case, a 10Fr catheter could not be passed through the stricture. Although there is no strict definition about the caliber of the urethral diameter, the inability to pass a $14 \mathrm{Fr}$ catheter is generally considered pathognomonic for the presence of a urethral stricture $[3,10,11]$. Cysto-urethroscopy is not possible in case of meatal or very distal urethral strictures [11], but it might directly visualize a more proximal stricture without providing information about the stricture length. Voiding cysto-urethrography (VCUG) is more informative about the stricture location and stricture length. Filling of the bladder is accomplished by either suprapubic access, if a suprapubic catheter has been placed, or by passing a small-caliber (e.g. $5 \mathrm{Fr}$ feeding tube) catheter through the stricture inside the bladder. During voiding, the urethra proximal to the stricture will show dilation with abrupt narrowing at the stricture site $[5,12]$. This so called "wine glass image" was clearly visible upon VCUG (Figure 2) and directly disappeared postoperatively (Figure 10). In case of any doubt of concomitant abnormalities (urethral diverticula, abscess formation, etc.), pelvic MRI is advised to diagnose or rule this out $[2,9,11]$.

No guidelines exist on which diagnostic modalities must be used during the work-out [3], but before start of urethroplasty, the surgeon should have sufficient information on the presence, extent and location of the stricture as well as on the quality of surrounding structures in order to be prepared for the urethroplasty.

The patient in the present case underwent numerous dilations and internal urethrotomies. This initial trial with endoluminal treatments is common practice in female urethral stricture disease despite disappointing long-term results. Based on a systematic review of Osman et al., the composite success rate was only $47 \%$ but should be considered even too optimistic as most of these women underwent intermittent catheterization which is a surrogate form of dilations [11]. All types of urethroplasty are associated with a higher success rate. Vaginal flap urethroplasty, vaginal/labial graft urethroplasty and oral mucosa graft urethroplasty have a composite success rate of respectively 91\%, 80\% and 94\% [11]. No large and well-conducted comparative trials have been performed to evaluate whether one technique is superior to another, whether the dorsal location is better than the ventral one or whether a specific type of graft performs better than the others. As a consequence no, general recommendations exist on which technique to choose [13]. In this case, we opted for buccal mucosa. This was in part the preference of the surgeon who is familiar with harvesting buccal mucosa for male urethral stricture disease. Vaginal mucosa seemed not suitable as the local vaginal tissues were inflammatory. The dorsal approach was opted here above the ventral approach. Again, because of the inflammatory vaginal tissue at the ventral aspect of the urethra, we estimated that the dorsal side of the urethra would be a more secure graft bed. Furthermore, because of pain, we opted to resect this abnormal tissue and we feared for paucity of local tissue to cover an eventually placed ventral graft. In this case, a Martius fat flap would be an option but this add to the morbidity of the operation (labial hematoma, cosmetic labial problems, decreased sensitivity, local pain) and was not preferred by the patient after discussing the options $[14,15]$. On the other hand, ventral procedures are reported technically easier to perform [11]. Nevertheless, we experienced no specific technical challenges during the dorsal approach performed herein. Another theoretic advantage of the ventral approach is the reduced risk of stress urinary continence because of the omega-shape of the female urethral sphincter with its ventral midline deficiency $[3,9]$. However, this hypothesis seems to be solely theoretical as no excess in stress urinary incontinence has been reported with dorsal procedures so far [11]. Our patient also reported no incontinence, despite this dorsal approach. Another concern with the dorsal approach is the risk of bleeding and damage to the clitoral bodies [3]. The fear of injury to the clitoral neurovascular bundle seems not to be justified [11]. We experienced no problems with this during the operation herein reported. In this case, the graft was meshed to allow fluid evacuation and quilted against the graft bed to ensure a close contact between the graft and the graft bed. A close contact between the graft and a well-vascularized graft bed is an important prerequisite in graft urethroplasty [16].

This case shows that a surgeon performing female urethroplasty should master different techniques in order to be able to adapt his technique to the local circumstances. In this case we opted for a dorsal approach because of poor quality of the ventral tissues. However, in case of the opposite situation, a ventral approach might be more suitable. Therefore, these techniques should not be regarded as competitive to each other but more complementary in the armamentarium of the reconstructive surgeon. The duration of urethral catheterization varies among series but is usually $2-3$ weeks $[7,9,13]$. In this 
case, we maintained the catheter for 2 weeks and used VCUG upon catheter removal to exclude extravasation. This is inspired from our experience in males [17]. Vaginal packing during $24 \mathrm{~h}$ is also advised by others for hemostatic reasons [10]. Longer follow-up of this case is needed because grafts might have the tendency to retract with time and long-term results in male have showed a steady deterioration [18].

\section{Conclusions}

This case showed the initial success of dorsal onlay urethroplasty with a buccal mucosa graft in a female with a urethral stricture refractory to endoluminal treatments. Longer follow-up and larger, preferable comparative series are needed to define the exact place of this technique in female urethroplasty.

\section{References}

1. Ackerman AL, Blaivas J, Anger JT (2010) Female Urethral Reconstruction. Curr Bladder Dysfunct Rep 5(4): 225-232.

2. Faiena I, Koprowski C, Tunuguntla H (2016) Female Urethral Reconstruction. J Urol 195(3): 557-567.

3. Hoag N, Chee J (2017) Surgical management of female urethral strictures. Transl Androl Urol 6(Suppl 2): S76-S80.

4. Patel DN, Fok CS, Webster GD, Anger JT (2017) Female urethral injuries associated with pelvic fracture: a systematic review of the literature. BJU Int 120(6): 766-773.

5. Singh M, Kapoor R, Kapoor D, Kapoor R, Srivastav A, et al. (2013) Dorsal onlay vaginal graft urethroplasty for female urethral stricture. Indian J Urol 29(2): 124-128.

6. Gormley EA (2010) Vaginal flap urethroplasty for female urethral stricture disease. Neurourol Urodyn 29 Suppl 1: S42-S45.

7. Powell CR, Daniels D (2017) Dorsal Onlay Buccal Urethroplasty in the Female is Associated with High Quality of Life Using Validated Lower Urinary Tract Symptom Instruments. Urology Practice 4(1): 48-53.
8. Montorsi F, Salonia A, Centemero A, Guazzoni G, Nava L, et al. (2002) Vestibular flap urethroplasty for strictures of the female urethra. Impact on symptoms and flow patterns. Urol Int 69(1): 12-16.

9. Mukhtar BMB, Spilotros M, Malde S, Greenwell TJ (2017) Ventral-onlay buccal mucosa graft substitution urethroplasty for urethral stricture in women. BJU Int 120(5): 710-716.

10. Osman NI, Chapple CR (2015) Contemporary surgical management of female urethral stricture disease. Curr Opin Urol 25(4): 341-345.

11. Osman NI, Mangera A, Chapple CR (2013) A systematic review of surgical techniques used in the treatment of female urethral stricture. Eur Urol 64(6): 965-973.

12. Heising J, Seiferth J (1978) Meatus stenosis of girls--clinical demonstration and therapy (author's transl). Urologe A 17(5): 292295.

13. Petrou SP, Rogers AE, Parker AS, Green KM, McRoberts JW (2012) Dorsal vaginal graft urethroplasty for female urethral stricture disease. BJU Int 110(11 Pt C): E1090-E1095.

14. Malde S, Spilotros M, Wilson A, Pakzad M, Hamid R, et al. (2017) The uses and outcomes of the Martius fat pad in female urology. World J Urol 35(3): 473-478.

15. Wilson A, Pillay S, Greenwell T (2017) How and why to take a Martius labial interposition flap in female urology. Transl Androl Urol 6(Suppl 2): S81-S87.

16. Oosterlinck W, Lumen N, Van Cauwenberghe G (2007) Surgical treatment of urethral stenoses: technical aspects. Ann Urol (Paris) 41(4): 173-207.

17. Poelaert F, Oosterlinck W, Spinoit AF, Lumen N (2017) Duration of urethral catheterization after urethroplasty: how long is enough? Minerva Urol Nefrol 69(4): 372-376.

18. Andrich DE, Dunglison N, Greenwell TJ, Mundy AR (2003) The longterm results of urethroplasty. J Urol 170(1): 90-92.

Your next submission with Juniper Publishers
will reach you the below assets
- Quality Editorial service
- Swift Peer Review
- Reprints availability
- E-prints Service
- Manuscript Podcast for convenient understanding
- Global attainment for your research
- Manuscript accessibility in different formats
( Pdf, E-pub, Full Text, Audio)
- Unceasing customer service
Track the below URL for one-step submission
https://juniperpublishers.com/online-submission.php

